\title{
Load-carrying capacity and failure modes of glulam beams with reinforced notches
}

\author{
Robert Jockwer $^{1}$ (i) $\cdot$ René Steiger $^{1} \cdot$ Andrea Frangi $^{2} \cdot$ Erik Serrano $^{3}$
}

Received: 15 February 2015/Published online: 28 August 2015

(C) Springer-Verlag Berlin Heidelberg 2015

\begin{abstract}
The structural behaviour and failure mechanisms of unreinforced and reinforced notched glulam beams were studied in a test series. It could be shown that shear failure of the reinforced notched beam is an important failure mechanism and that adequate reinforcement in tension perpendicular to grain and shear is required in order to regain the load-carrying capacity of the reduced crosssection of the glulam beam.
\end{abstract}

\section{Introduction}

Notches considerably reduce the load-carrying capacity of beams due to the stress concentrations around the notch corner. In order to prevent brittle failure and to increase the load-carrying capacity, notches should be reinforced. Design approaches to determine the force acting in the reinforcement only account for the tensile force perpendicular to the grain acting in the notch corner (e.g. DIN 2013). The shear force acting in the notch corner is not taken into account in the existing approaches. However, the shear force is of relevance for the load-carrying capacity of the reinforced notched beam as discussed by Jockwer (2014).

Robert Jockwer

robert.jockwer@empa.ch

1 Structural Engineering Research Laboratory, Empa, Swiss Federal Laboratories for Materials Science and Technology, Ueberlandstrasse 129, 8600 Dübendorf, Switzerland

2 Institute of Structural Engineering, ETH Zurich, StefanoFranscini-Platz 5, 8093 Zürich, Switzerland

3 Division of Structural Mechanics, Lund University, Box 118, 22100 Lund, Sweden
The contribution of shearing on the failure of notched beams was studied in a test series with different kinds of reinforcement under different angles of inclination of the reinforcement.

\section{Experiments}

A test series was performed on notched beams with different types and inclinations of reinforcing elements.The geometrical parameters of the notched beams are illustrated in Fig. 1. The beams were loaded in three point bending with a distance between load application and notched support of $1150 \mathrm{~mm}$. The timber for the specimens was ordered according to the Nordic strength class L40c. Fully threaded self-tapping screws of type SFS WR-T-13 with a diameter of $d=13 \mathrm{~mm}$ and unidirectional carbon fibre sheet of type SikaWrap 230C/ 45 with a width of $50 \mathrm{~mm}$ were used as reinforcing elements with inclinations $\gamma=90^{\circ}$ and $\gamma=45^{\circ}$ with respect to the beam axis (Fig. 1). The material properties of the reinforcing elements can be found in European Organisation for Technical Approvals EOTA (2012) and Sika (2011). The tests were carried out at LNU Växjö, Sweden.

The following parameters were measured: applied force, deflection of the beam at the load transfer point, crack opening and shearing displacement at the notch corner, displacement field of the surface of the notch corner by means of digital image correlation (DIC).

\section{Results}

In Fig. 2 the reaction forces averaged over the reduced cross-section of the unreinforced notched beams and notched beams reinforced by means of fully threaded self- 


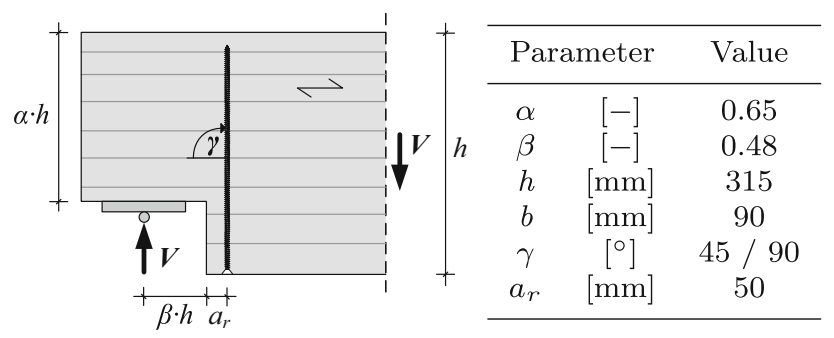

Fig. 1 Geometrical parameters of the tested notched beams

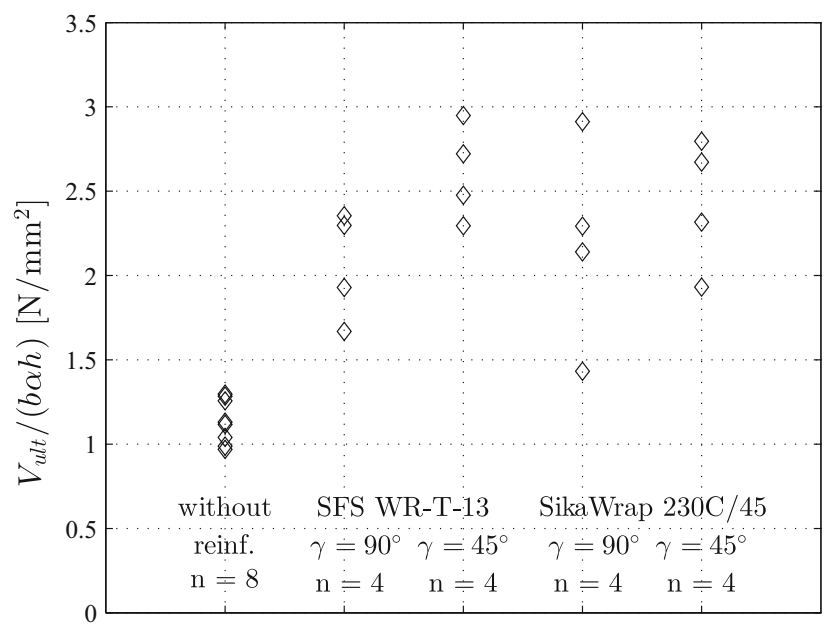

Fig. 2 Ultimate reaction forces averaged over the reduced crosssection of the notched beams $V_{u l t} /(b \alpha h)$

tapping screws and unidirectional carbon fibre sheets are shown. The notches without any reinforcement failed in a brittle way at comparably low loads. Crack opening was the apparent failure mechanism in these tests. The reinforced notches reached higher ultimate loads and distinct stable crack growth occurred before reaching ultimate load. In the specimens reinforced by means of fully threaded self-tapping screws, the reinforcement exhibited sufficient strength to prevent the lower parts of the beams from falling off even after failure of the notch with unstable crack growth. Crack opening was limited by the reinforcement and after excessive crack growth even a closure of the crack could be observed.

In tests with carbon fibre reinforcement the CFR sheets peeled off at ultimate failure. The reinforcement with $\gamma=$ $90^{\circ}$ failed in the bondline between CFR and timber in the lower part of the notch. The reinforcement with $\gamma=45^{\circ}$ failed in the bondline in the upper part of the notch. The tensile strength of the reinforcement could not be activated in the tests.

The DIC measurements of the displacement fields were evaluated with regard to the opening and shearing displacement of the crack. Remarkable shear deformation of the crack was observed with increasing load at a distance from the notch corner at which there was no crack opening. Hence, pure mode 2 fracture of the crack can be assumed.

\section{Discussion and conclusion}

In the tests failure of the notches is initiated by increasing crack growth starting in the notch corner. The reinforcement prevents excessive crack opening. The failure of the reinforced notch due to excessive crack growth at ultimate load is caused by shear failure of the crack.

The load-carrying capacity of notches without reinforcement can be estimated applying the EC5 design approach by Gustafsson (1988). Using the mode 1 fracture energy, also the load at initial cracking of the reinforced notches tested can be predicted with this approach. Loadcarrying capacities of the notches reinforced perpendicular to the grain were approximately two times higher in experiments compared to the unreinforced notches. This coincides well with the prediction of the load-carrying capacities estimated with the EC5 design approach when using the mode 2 fracture energy instead of the mode 1 fracture energy.

In numerical investigations a dependency of the ratio of mode 1 and mode 2 loading at the crack tip with the crack length was found by Jockwer (2014) also for other geometries of the notch. It could be shown that crack initiation is caused by mode 1 fracture and failure by mode 2 fracture.

Acknowledgments The support of this project by COST Action FP 1004 is gratefully acknowledged.

\section{References}

DIN (2013) DIN EN 1995-1-1/NA: National Annex-nationally determined parameters-Eurocode 5. Deutsches Institut für Normung e.V, Berlin

European Organisation for Technical Approvals EOTA (2012) ETA12/0062. SFS self-tapping screws WR, Österreichisches Institut für Bautechnik, Vienna

Gustafsson PJ (1988) A study of strength of notched beams. In: Proceedings of the CIB-W18 Meeting 21, Parksville, Canada, Paper no. 21-10-1

Jockwer R (2014) Structural behaviour of glued laminated timber beams with unreinforced and reinforced notches. $\mathrm{PhD}$ thesis, Institute of Structural Engineering, ETH Zurich, Switzerland

Sika (2011) SikaWrap-230C/45, Woven carbon fiber fabric for structural strengthening product data sheet. Sika Schweiz AG, Zurich, Switzerland 